\title{
DESCRIPTION OF PROCESS IN AQUEOUS SOLUTIONS: DIFFERENCES BETWEEN XIX AND XX CENTURIES CONCEPTIONS
}

\section{DESCRIÇÃO DE PROCESSOS EM SOLUÇÃO AQUOSA: DIFERENÇAS ENTRE OS CONCEITOS DO SÉCULOS XIX E XX}

\author{
A.F. OLIVEIRA ${ }^{1 *}$, R.L PEREIRA ${ }^{1}$, M. FLORES-JR ${ }^{2}$, A.A. NEVES ${ }^{1}$ AND M.E.L.R.QUEIROZ ${ }^{1}$ \\ ${ }^{1}$ Universidade Federal de Viçosa, Department of Chemistry, Viçosa, MG, Brazil \\ ${ }^{2}$ Arclin Surfaces, Hayward, WI, USA
}

${ }^{*}$ Corresponding author. Universidade Federal de Viçosa, Department of Chemistry, Viçosa, MG, Brazil Phone: +55 $313899-4877$

e-mail address: andref.oliveira@ufv.br (A. F. Oliveira).

\begin{tabular}{l} 
A R T I C L E I N F O \\
\hline Article history: \\
Received 2018-10-10 \\
Accepted 2019-02-06 \\
Available online 2019-03-08 \\
pa la vra s-ch a ve \\
Solução química aquosa \\
Equilíbrio químico \\
Conceitos errados \\
Equações químicas \\
ke yw o r $d s$ \\
Aqueous Chemical Solution \\
Chemical Equibria \\
Misconceptions \\
Chemical Equation
\end{tabular}

A R T I C L E I N F O

Accepted 2019-02-06

Solução química aquosa

Equilíbrio químico

Conceitos errados

keywords

Chemical Equibria

Chemical Equation

\begin{abstract}
A B S T R A C T
We showed some inconsistencies in the teaching of Chemistry of Solution in universities by proposing that historical development of research of Chemistry of Solutions occurred with the formation of two distinct concepts, the XIX century concept, and the XX century concept. XIX century concept was created before the Arrhenius' electrolytic theory and it did not consider the real chemical species in solution. The differences between these concepts can seem subtle at a glance, but some examples are shown to clarify them, as well as the problems with use the XIX century concept nowadays. The examples involve differences in chemical equations writing, Henderson-Hasselbach Equation, Arrhenius' Ionization degree, Acid-base and solubility equilibria.
\end{abstract}

RES UM O/R ES UMEN

Nós apresentamos algumas inconsistências no ensino da Química de Soluções nas universidades, propondo que o desenvolvimento histórico da pesquisa em soluções químicas ocorreu com a formação de dois conceitos distintos, o conceito do século XIX e o conceito do século XX. O conceito do século XIX foi criado antes da teoria eletrolítica de Arrhenius e não considerou as espécies químicas reais em solução. As diferenças entre esses conceitos podem parecer sutis à primeira vista, mas alguns exemplos são mostrados para esclarecê-las, bem como os problemas com o uso do conceito do século XIX nos dias atuais. Os exemplos envolvem diferenças na escrita de equações químicas, na Equação de Henderson-Hasselbach, no grau de Ionização de Arrhenius e nos equilíbrios ácido-base e de solubilidade. 


\section{INTRODUCTION}

When studying chemical equilibrium in solution, it is very common to observe subtle inconsistences in some conceptions presents in some textbooks. The description of conceptions like Arrhenius and Bronsted Acids and Bases, degree of ionization or dissociation, analytical concentration, among others, are frequently confusing and may pose a problem for educators and students. We believe that part of this confusion is related to the use of two distinct historic conceptions about description of chemical species in aqueous solution, which we called "XIX Century Conception" and the other "XX Century Conception".

The XIX Century Conception (and those before that) did not consider the importance of the solvent, as seen in the works done independent by Van't Hoff and Raoul about colligative properties. In such works, the solution was considered a medium like a gas and, therefore, would obey the Ideal Gas Law although with some modifications/ corrections (BAUER, 1933).

Another important aspect of this conception is that the description of a solution is focused only on the components added to it. The solvent in which these components were added to be completely ignored, as if there were no changes in solution compared to initial composition. It happened because it was necessary separation and purification the products (distillation, dryness, etc.) (FREUND, 1904; LEICESTER,1956). In other words, they only had access to solid compound and not chemical species in solution. For example, we can regard the old "double replacement reaction" ("metathesis") where a mixture of a silver nitrate solution with a sodium chloride solution causes the formation of solid of silver chloride. In this conception, the sodium nitrate was formed, too (Eq.1).

$$
\mathrm{AgNO}_{3}+\mathrm{NaCl} \rightarrow \underline{\mathrm{AgCl}}+\mathrm{NaNO}_{3}
$$

Even, some more recent edition textbooks (BROWN et al.,2011; KOTZ et al., 2012) reinforce that XIX Century Conception. It means, they consider that the compound added or removed from solution (by filtration and evaporation, by example) really exist in solution, once they put the subscript "aq" in the compounds, as $\mathrm{AgNO}_{3(\mathrm{aq})}, \mathrm{NaCl}_{(\mathrm{aq})}$ or $\mathrm{NaNO}_{3(\mathrm{aq})}$. And it is wrong, due complete dissociation of these salts in aqueous solutions

$$
\mathrm{AgNO}_{3(a q)}+\mathrm{NaCl}_{(a q)} \rightarrow \mathrm{AgCl}_{(s)}+\mathrm{NaNO}_{3(a q)}
$$

This misconception is due a historical lack, it means, the experimental conditions was forgotten, which informations about what have happened to a solution only would be obtained just after the removal and separation of the solids formed in it. Thus, the wrong conclusion was that there was a compound sodium nitrate in solution because it was recovery after the solvent evaporation.

It is interesting remember that Berthollet (in beginning of XIX century) observed inconsistence in this procedure with his initial idea about equilibrium, but he was an only voice in his time, when everyone was focused on compound add to solutions and solid compounds obtained from solution (SZABADRARY, 1996, PARTINGTON, 1961, FREUND, 1904).

This cited misconception was also observed in usual expressions like: "The initial concentration of acetic acid in aqueous solution is equal to ... and it was partially dissociated in ions." The term "initial" is actually, other meaning.

From historical view, gradually though, new techniques were developed to study chemical species directly in solutions. Those developments happened mostly in the second middle of the XIX century, thanks to innovative conceptions such as those presented in influence of solutions properties on polarized light, in Kohlrausch's electric conductivity, Hittorf's transport number, Peters-Nernst electric potential, etc. (SZABADRARY, 1996, PARTINGTON, 1961; MacINNES, 1939). It can be said that the introduction of Arrhenius electrolytic dissociation theory (1884) was a millstone indicating the beginning of the paradigm shift from solution of the XIX Century Conceptions. Arrhenius presented important evidences about the presence of ions in solution when an electric field is absent. As expected, in his writings Arrhenius utilized the XIX Century Conceptions to explain the ions formation and to define and classify acid and base. According to his theory, an acid-base behavior can be explained: an acid is a substance that dissociates when add to solution/water producing hydrogen ions or protons $\left(\mathrm{H}^{+}\right)$; a base is a substance that dissociates when add to solution/water producing hydroxide ions $\left(\mathrm{OH}^{-}\right)$. Likewise, a salt may be acid or alkaline depending on its ability to increase or decrease the concentration of hydrogen or hydroxide ions when added to solution. For example:

$$
\begin{aligned}
& \mathrm{HAc}_{(a q)} \leftrightharpoons \mathrm{Ac}_{(a q)}^{-}+H_{(a q)}^{+} \quad \mathrm{pKa} \\
& \mathrm{NaOH}_{(s)} \longrightarrow \mathrm{Na}_{(a q)}^{+}+\mathrm{OH}_{(a q)}^{-}
\end{aligned}
$$

Thus, according to this theory the acetic acid and sodium hydroxide are acid and base of Arrhenius, because, once they are added to solution, they released protons or hydroxide ion to it.

Conversely, the XX Century Conception concentrated in the behavior of chemical species in solution and the description of chemical species in it and there is a rather less concern about the compounds added to solution. In this conception, there was a need in explain why ions were stable in solution, how solvents behaved (solvation phenomena), its interactions with other chemical species, and an acid -basic classification for species in solution. (HALL, 1940; FRANKLIN, 1924; GERMANN, 1925).

Thus, in the metathesis reaction previously shown, the most important, a priori, is the equilibrium between silver and chloride ions and silver chloride solid. It does not matter if chloride ion was present in solution due dissolution and dissociation of sodium chloride or potassium chloride.

$$
A g C l_{(s)} \leftrightharpoons A g_{(a q)}^{+}+C l_{(a q)}^{-} \quad p K s
$$


If the Theory of Dissociation of Arrhenius was a milestone of the end of XIX Century Conception, the Bronsted Acid-Base system is an appropriate milestone when the XX Century Conception was well established. Proposed in 1923 (HALL, 1940) nowadays the Bronsted system defined an acid as any chemical species in solution that can donate a proton, and a base as any chemical species in solution able to be linked to a proton. Of course, this definition was mixed of Bronsted-Bjerrum-Lowry acid base system, with Franklin-Germann Solvent System (FRANKLIN, 1924; GERMANN, 1925). Using acetic acid as example, its release of proton just occurs by formation of bond between proton and the solvent molecules.

$\mathrm{HAc}_{(a q)}+\mathrm{H}_{2} \mathrm{O}_{(\mathrm{l})} \leftrightharpoons A c_{(a q)}^{-}+\mathrm{H}_{3} \mathrm{O}_{(a q)}^{+} \quad p K a$

However, there are subtle differences between the theories proposed by Arrhenius and Bronsted. Bronsted system focus on behavior of the species in solution, while in the classification proposed by Arrhenius the important part is the chemical added to the solution. Besides, the importance of solvent is due its important participation in solvation process, even in formation of hydronium (specie postulated according the described behavior of solution known in that time). An interesting example is $\mathrm{NH}_{4}{ }^{+}$aq. (ammonium ion) in aqueous solution. It is classified as an acid as per BronstedLowry theory, while Arrhenius does not classify the ion, but its salt, ammonium chloride, as an acid salt.

\section{CONSEQUENCES OF CONCEPTIONS CONFUSION}

These different perspectives difficult the interpretation of some phenomena, since explanations provided by both are contradictory in many cases, as seen in the following examples.

\subsection{Equivocation in the Description of Processes by Equations}

The conception adopted to explain a chemical reaction has great influence in the way equations are written as, for instance, the reactions of double-rearrangement, widespread in the nineteenth century. An example illustrating this kind of reaction involves the formation of a low watersoluble salt, lead iodide, by the mixture of lead nitrate and potassium iodide. Some current texts present Equation 1 to describe this process; (MCCUTCHEON et al., 1939; BROWN et al.,2011; KOTZ et al., 2012).

$\mathrm{Pb}\left(\mathrm{NO}_{3}\right)_{2(a q)}+2 \mathrm{KI}_{(a q)} \rightarrow \mathrm{PbI}_{2(s)}+2 \mathrm{KNO}_{3(a q)}$

It can be seen in Equation (1) that the 'aqueous' phases placed in parentheses for the ionic compounds, as already cited, emphasize the conception of the XIX century, that is, it is as if these chemically bound compounds existed in solution. In the conception of the XX century, this reaction does not make sense from a chemical point of view, because with the total dissociation of the ions in solution, there is no regrouping thereof creating a solvated compound, that is, potassium nitrate in solution. Per the twentieth century approach, a better representation of the system would be made through distinct equations.

$$
\begin{aligned}
& \mathrm{Pb}\left(\mathrm{NO}_{3}\right)_{2(s)} \rightarrow \mathrm{Pb}_{(a q)}^{2+}+2 \mathrm{NO}_{3(a q)}^{-} \\
& \mathrm{KI}_{(s)} \rightarrow \mathrm{K}_{(a q)}^{+}+I_{(a q)}^{-} \\
& \mathrm{PbI}_{2(s)} \leftrightharpoons 2 I_{(a q)}^{-}+\mathrm{Pb}^{2+}{ }_{(a q)}
\end{aligned}
$$

Therefore, the chemical Equations 2 and 3 describe the complete dissociation and dissolution processes of ionic compounds. The last equation shown the solubility equilibrium of lead (II) iodide, which is independent of other chemical equations.

Table 1. Acid-base equilibria represented by chemical equations by XIX and XX centuries concepts.

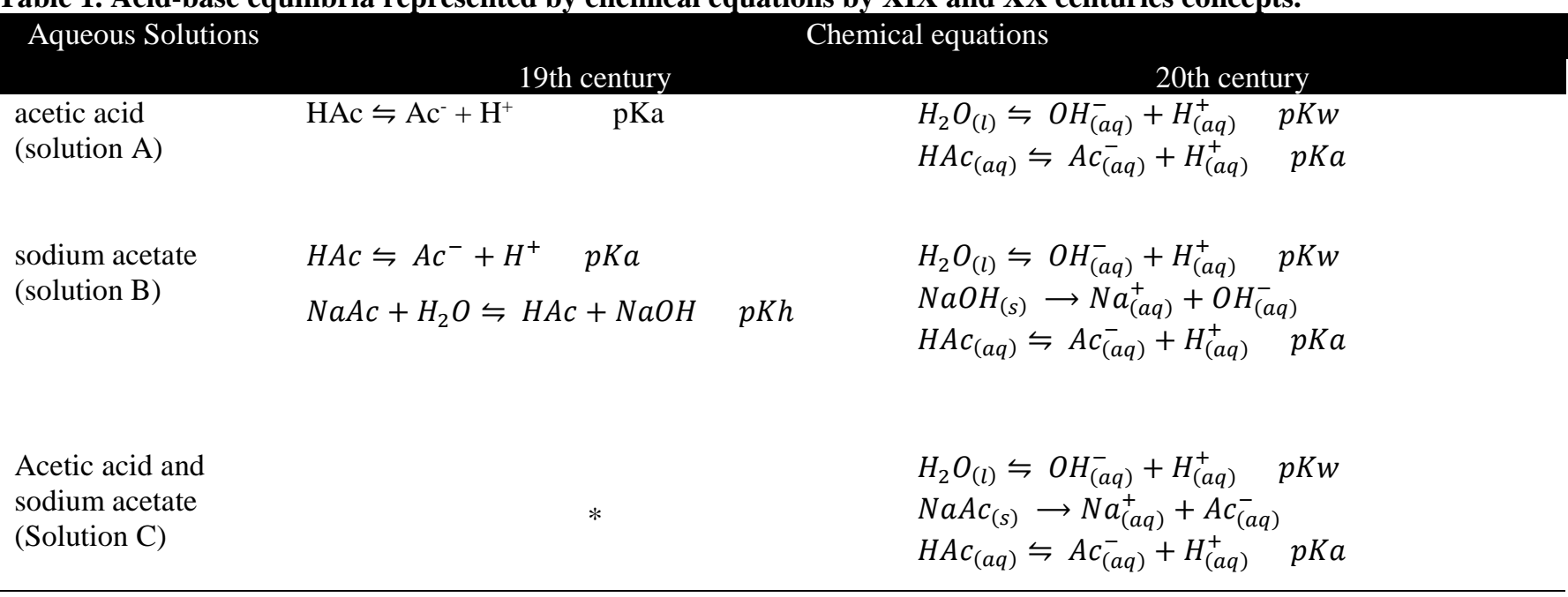

\subsection{Acid-Base Equilibria}

Let us take the addition of acetic acid and/or sodium acetate in water as an example to discuss the acid-base 
equilibria. The Table 1 presents the chemical equations that describe different solutions from both of point of view, 19th and 20th centuries.

Considering the behavior of sodium acetate (Solution B), under the conception of the 19th century, the argument is that the salt dissociates and the anion undergoes hydrolysis in solution, suggesting implicitly that this process is distinct from acetic acid equilibrium (solution $\mathrm{A}$ ). In this case, which equation (solution A or B) would describe the solution C? And, consequently, what is the constant? If the answer is "either one of them", you could ask a new question: in solution B, could the equation of solution A be used instead?

Under the twentieth century concept, these same solutions always consider the complete dissociation of sodium acetate and, considering Bronsted acid-base equilibrium, this will be the same for all solutions containing the species taking part in the equilibrium. That is true even if "apparently" only one species exists, that is, if there is acetate ion in solution (solution B), so that acetic acid must exist, even though at a relatively low concentration when the reaction is in equilibrium. The chemical equation shown only the chemical species (and its phases) and the relationship between them, but it must no show any information about concentration of each specie. One must note that the equilibrium of auto ionization of water is always present.

It is interesting to note that use of constants $\mathrm{Kb}$ and $\mathrm{Kh}$ (base constant and hydrolysis constant, respectively) are also consequences of the nineteenth-century concept of solution. As shown in Table 1, the Kh constant was just used because that equation (or similar) was used. Besides, in that time, it was usual to consider the acid or basic behavior of a neutral organic species.

In the twentieth century concept, for the sake of practicality and to avoid confusion with duplication of constants, it was adopted the use of the acid dissociation constant (or acidity) $\mathrm{Ka}$ (and its $\mathrm{pKa}$, even more practical) instead of other constants (DEAN, 1999). Thus, acid-base Bronsted equations are always written as a Bronsted acid forming its conjugated Bronsted base.

In relation to use of $\mathrm{H}_{3} \mathrm{O}_{(\text {aq })}$ or $\mathrm{H}_{(a q)}^{+}$, it must be remembered that in the year 1957, Eigen tried to prove the existence of hydronium using a method of relaxation in ultrasound. Instead, he proved the specie of water bonded to proton was the eigen ion $\left(\mathrm{H}_{9} \mathrm{O}_{4}{ }^{+}\right)$. Until today there is a discussion about the behavior and distribution of the several proton hydrates $\left(\left(\mathrm{H}_{(}\left(\mathrm{H}_{2} \mathrm{O}\right)_{\mathrm{n}}{ }^{+}\right)\right.$(MARX et al., 1999; VENER et al., 2009; OLIVEIRA, 2009). Strictly, the main proton hydrate in solution and the classical Bronsted of acid-base equation system leaves to an impasse in written of chemical equations. For example:

$$
\begin{aligned}
& \mathrm{HNO}_{2(a q)}+\mathrm{H}_{2} \mathrm{O}_{(l)} \leftrightharpoons \mathrm{NO}_{2(a q)}^{-}+\mathrm{H}_{3} \mathrm{O}_{(a q)}^{+} \\
& \mathrm{HNO}_{2(a q)}+2 \mathrm{H}_{2} \mathrm{O}_{(l)} \leftrightharpoons \mathrm{NO}_{2(a q)}^{-}+\mathrm{H}_{5} \mathrm{O}_{2(a q)}^{+} \\
& \mathrm{HNO}_{2(a q)}+4 \mathrm{H}_{2} \mathrm{O}_{(l)} \leftrightharpoons \mathrm{NO}_{2(a q)}^{-}+\mathrm{H}_{9} \mathrm{O}_{4(a q)}^{+}
\end{aligned}
$$

The impasse was removed considering water is always omitted when possible, for simplicity. In addition, the solvated proton $\mathrm{H}^{+}$(aq) represents all its hydrates (hydronium, Zündel Ion, Eigen ion, etc.) (OLIVEIRA, 2009). This convention is very useful because simplified the chemical equation and it considers all hydrates of proton instead of wrongly choose one. Besides, it permits always written, without ambiguity, the conjugated Bronsted acid forming the conjugated Bronsted base, and so, it uses the right constant pKa.

\subsection{Dissociation Degree}

To carry out the studies that lead to the theory of electrolytic dissociation, Arrhenius defined the degree of dissociation $(\alpha)$ of a chemical in a solution, it means, the fraction of that chemical that would be ionized in the solution. For such, Arrhenius used electrical conductivity measurements (among other types of measurements) and postulated that the ionization (or dissociation) of a chemical would be proportional, by example, to the conductivity of the solution and that, in very dilute solutions, dissociation would be complete.

Thus, when adding a chemical compound in solution, its degree of ionization degree $\left(\alpha_{i}\right)$ at that specific concentration is obtained by the ratio between measured conductivity $\left(\Lambda_{\mathrm{i}}\right)$ and the limit conductivity $\left(\Lambda_{\mathrm{o}}\right.$, or conductivity at infinite dilution), which is the estimated molar conductivity for the fully dissociated (or ionized) chemical. The use of electrical conductivity for study of solutions was well established at the time, based on the results and laws of Kohlrausch, (MacINNES, 1939).

$$
\alpha(i)=\frac{\Lambda_{\mathrm{i}}}{\Lambda_{o}}
$$

Thus, when adding acetic acid in water to obtain a 1 $\mathrm{mmol} / \mathrm{L}$ solution, Arrhenius had a degree of dissociation of $13.3 \%$ at $25^{\circ} \mathrm{C}$ (MCCUTCHEON et al., 1939). For the nineteenth-century interpretation, $13.3 \%$ of the added acetic acid was dissociated as if in that prior situation there was no dissociation. Besides, the analytical concentration was the "initial" concentration of acetic acid, or the concentration "before the dissociation". On the other hand, for the twentiethcentury concept presented in many modern texts, the degree of dissociation is defined as:

$$
\alpha(i)=\frac{[i]}{c(i)}
$$

Where [i] refers to the equilibrium concentration of the species 'i' and 'c(i)', the analytical concentration of this species (OLIVEIRA, 2009; HARRIS, 2010).

On the XX Century, the concept of analytical concentration became clear, proposing that when a system is in equilibrium, the real concentration of species can be determined by some sort of chemical equilibrium. The analytical concentration is the sum of the equilibrium concentrations of all species belonging to a same system in equilibrium. For example, the analytical concentration of acetate is equal to the analytical concentration of acetic acid, because they belong to the same acid-base equilibrium system, and then, these concentrations are equal to sum of equilibrium concentrations of acetic acid and acetate.

$$
c(H A c)=c\left(A c^{-}\right)=[H A c]+\left[A c^{-}\right]
$$

This concept allows a clearer and broader definition of the system mentioned in the previous example, considering the behaviour of a particular chemical species and the many equilibria equilibrium that it participates in solution. Again, attention is no longer in the chemical compound (or compounds) which were added to obtain that solution. In this way, the degree 
of dissociation of acetic acid as defined by the twentieth century concept is $86.7 \%$ while the degree of dissociation of acetate is equal to $13.3 \%$. Thus, the term 'degree of dissociation' (or ionization) has two opposing meanings.

This definition is the same independent of changes in solution or addition of several other species. For example, if the $\mathrm{pH}$ of the solution formed by the mixture of acetic acid and sodium acetate is adjusted to 3.93, the degree of dissociation of acetic acid will be $86.7 \%$.

The very term "degree of dissociation" or "degree of ionization" is also a result of the nineteenth-century concept because the terms "dissociation" and "ionization" refer, implicitly, to the process that will occur with a chemical compound is added to a solution. In this sense, some other terms have been proposed, such as "degree of association" (HARRIS, 2010). Therefore, there are a semantic problem with these names.

Some names have been proposed for their replacement, such as "molar fraction" or "mole fraction", but since this is already used to describe another type of concentration, it cannot be used. Compositional fraction was also proposed, although it is used to describe food composition. The term "equilibrium fraction" seems to be a reasonable name.

\subsection{Henderson-Hasselbach Equation}

Proposed to explain the blood buffering behavior by Hasselbach in 1906 and generalized by Henderson in 1912 (PO, 2001; LEVIE, 2002), the equation of Henderson-Hasselbach also brings discrepancy when interpreted by the two views, i.e. by XIX and XX Century Conceptions. The XIX conception presents the solution formed by the addition of sodium acetate and acetic acid to the water as a solution with $\mathrm{pH}$ defined by the equation (VOGEL et al.,1979):

$$
p H=p K a+\log \frac{" c(\text { salt }) "}{" c(\text { acid }) "}
$$

From the point of view of the nineteenth century (chemical equations in Table 1), the concentration of acetic acid, "c (acid)", has no direct correlation with the concentration of sodium acetate, "c (salt)". That is because, in this concept, "c (acid)" is the concentration of the acid acetic added to the solution (as if it is not partially converted in acetate) and "c (salt)" is the concentration of acetate provided by sodium acetate (as if it also does not contribute to acid acetic analytical concentration). It is difficult do not agree the situation is confuse.

Thus, it is difficulty to describe what type of concentration should be used, since it is neither the concentration of equilibrium nor the analytical concentration of acetic acid. Besides, the nineteenth century concept omits important considerations about the behavior of the species preset in solution and also does not provide explanations for special cases in which the equation can be used. In the same way, it has been seen that some books present the equation of Henderson Hasselbach as logarithmic form of Law of Action of Mass. However, there is still the problem of preparation of the solution, since the equilibrium concentration is directly related to the added amounts, i.e.:

$$
\text { "c(salt)" }\left[\text { Ac }^{-}\right] \text {e } " c(\text { Acid }) " \sim[H A c]
$$

\subsection{Solubility Equilibria}

The mixture of XIX and XX conceptions is usual in several analytical textbooks in solubility equilibria of ionic compounds. Using the addition of a sparingly soluble silver carbonate on water as example, the dissociation of ions is complete and then, there is no a specie $\mathrm{AgCO}_{3(\mathrm{aq})}$ in solution, but a complete dissociation of íons (Eq. 17).

$\mathrm{Ag}_{2} \mathrm{CO}_{3(s)} \leftrightharpoons 2 \mathrm{Ag}_{(a q)}^{+}+\mathrm{CO}_{3(a q)}^{2-} \quad$ pKs

However, one of exercises in such textbooks is calculation of solubility of salt, as this species exist in solution. This weird question is another example of nineteen century conception. The concentration of the salt added to solution, as it was not dissociated. The other usual term in this kind of equilibrium is the "common ion effect", used to explain the changing of equilibrium concentration of an ion when the concentration the other (contraion) is altered by addition of a soluble salt content the contraion.

\subsection{Presence of species that only exist in solids}

Probably because the understanding of a solution came from the understanding of the solids that would be removed from the solution, the ninetieth century concept considers that solids are still present in solution. As an example, consider the equation (VOGEL et al., 1979)

$$
\mathrm{Al}^{3+}+4 \mathrm{OH}^{-}(\text {excess }) \rightarrow \mathrm{AlO}_{2}^{-}+2 \mathrm{H}_{2} \mathrm{O}
$$

The ninetieth century concept considers the existence of aluminate $\left(\mathrm{AlO}_{2}^{-}\right)$in solution, since it is found only in a nonhydrated medium, as in a solid phase. In the twentieth century concept, aluminum hydroxocomplexes existing in solution, and aluminate, are anionic hydroxy complexes, like $\left(\mathrm{Al}(\mathrm{OH})_{4}^{-}(\mathrm{aq})\right)$.

The behavior of hydrolysis of metal in solution can be done considering the solvated metals $\left(\mathrm{Al}\left(\mathrm{H}_{2} \mathrm{O}\right)_{6}{ }^{3+}\right.$ as example) in solution as Bronsted acid. This approach is very interesting to study the behavior of system as function of $\mathrm{pH}$. It is important to emphasize that formalism of complexation equilibria is more correct, because it includes polynuclear complexes (but less usual). One possible chemical equation is

$$
\mathrm{Al}\left(\mathrm{H}_{2} \mathrm{O}\right)_{6(a q)}^{3+} \leftrightharpoons \mathrm{Al}\left(\mathrm{H}_{2} \mathrm{O}\right)_{5} \mathrm{OH}_{(a q)}^{2+}+H_{a q}^{+} \quad p K a_{1}=5.0
$$

Using the convention of omitting the water molecules in chemical equation, all molecules can be omitted, with exception that loses the proton. Then, all chemical equation about mononuclear hydroxocomplexes can be shown, including the solubility equilibrium of neutral hydroxocomplex (with its intrinsic solubility constant, $\mathrm{s}_{\mathrm{o}}$ )

$$
\begin{aligned}
& A l_{(a q)}^{3+}+H_{2} O_{(l)} \leftrightharpoons \mathrm{AlOH}_{(a q)}^{2+}+H_{a q}^{+} \quad p K a_{1}=4.99(21) \\
& \mathrm{AlOH}_{(a q)}^{2+}+\mathrm{H}_{2} \mathrm{O}_{(l)} \leftrightharpoons \mathrm{Al}(\mathrm{OH})_{2(a q)}^{+}+H_{a q}^{+} p K a_{2}=5.55(22) \\
& \mathrm{Al}(\mathrm{OH})_{2(a q)}^{+}+\mathrm{H}_{2} \mathrm{O}_{(\mathrm{l})} \leftrightharpoons \mathrm{Al}(\mathrm{OH})_{3(a q)}+\mathrm{H}_{a q}^{+} \\
& p K a_{3}=5.6(23) \\
& \mathrm{Al}(\mathrm{OH})_{3(a q)}+\mathrm{H}_{2} \mathrm{O}_{(\mathrm{l})} \leftrightharpoons \mathrm{Al}(\mathrm{OH})_{4(a q)}^{-}+H_{a q}^{+} \\
& p K a_{4}=6.5(24) \\
& A l(O H)_{3(s)} \leftrightharpoons A l(O H)_{3(a q)} \\
& -\log s_{o}=7.7(25)
\end{aligned}
$$


Accordingly, it is reasonable explain the presence of anionic species $\mathrm{Al}(\mathrm{OH})_{4}^{-}{ }_{(\mathrm{aq})}$ in solution, instead of improbable $\mathrm{AlO}_{2}^{-}$(aq).

The difference in two described concepts sometimes can lie subtles for those who already have more experience in chemistry and the transition between the two conceptions has become natural that almost never these discrepancies are observed.

Nowadays, a methodology totally based in XX concepts has been shown in Universidade Federal de Viçosa since 2010. Besides, a book also based in this methodology has been written. (OLIVEIRA, 2019)

\section{CONCLUSION}

These two antagonist concepts proposed permit explain the inconsistence in several modern textbook. These concepts, when not properly explained, difficult the understanding of chemical equilibrium and frequently impact the student education.

With the proper identification and understanding of these two concepts, it is possible can gradually eliminate or, at least, clarify its differences, facilitating the understanding of the process that happen in solution and, in special, chemical equilibrium. A proposed methodology of chemistry of solutions using only the newer concept are already applied in universities and a book describing it is in press, and it will help to improve the knowledgement about chemical species in solutions.

\section{R E F E R E N C E S}

BAUER, H. História de La Química (History of the Chemistry). Barcelona: Labor, 1933. (in Spanish)

BROWN, T. E.; LEMAY, H. E. H.; BURSTEN, B. E.; WOODWARD, P.; MURPHY, C. Chemistry - The Central Science. $12^{\text {th }}$ ed.; New York: Prentice Hall, 2011.

DEAN, D.A. Lange's Handbook, $15^{\text {th }}$ ed., Boca Raton: CRC, 1999.

FRANKLIN, E. C., Systems of acids, bases and salts J. Am. Chem. Soc., v. 46, n.10, p. 2137-2151.1924.

FREUND, I. The study of chemical composition and account of its methods and historical development with illustrative quotations. Cambridge: University.

GERMANN, A.F.O. A general theory of solvent systems J. Am. Chem. Soc., v.47, n.10, p. 2461-2468. 1925.

HALL, F. N., Systems of acids and bases J. Chem. Ed., v. 40 n.3, p. 124-128. 1940.

HARRIS, D. C. Quantitative Chemical Analysis. $8^{\text {th }}$ ed., N. York: W. H. Freeman, 2010.

KOLTHOFF, I.M., Acid-Base Indicators. New York: MacMillan, 1937.

LEICESTER, H. M. The Historical Background of Chemistry, N. York: Dover, 1956.

KOTZ, J.C.; TREIC HEL, P.M.; TOWNSEND, J.R. Chemistry \& Chemical Reactivity. $8^{\text {th }}$ ed., Belmont: Cengage Learning, 2012.

LEVIE, R. The Henderson Approximation and the Mass Action Law of Guldberg and Waage Chem. Educator, v. 7, n. 3, p. 132-135. 2002.
MacINNES, D. A. The Principles of Electrochemistry. New York: Reinhold, 1939.

MARX, D.; TUCKERMAN, M.E.; PARRINELLO, J.H.M, The nature of the hydrated excess proton in water, Nature, v. 397, p. 601-604.1999.

MCCUTCHEON, T. P.; SELTZ, H; WARNER, J.C. General Chemistry. $3^{\text {rd }}$, New York: Van Nostrand 1939.

OLIVEIRA, A. F. Equilíbrio Químico em Solução Aquosa (Chemical Equilibrium in Aqueous Solution) Campinas: Átomo, 2009. (in Portuguese)

OLIVEIRA, A. F. Química de Soluções - Avaliação de Equilíbrios Químicos em solução Aquosa (Chemistry of Solutions - Evaluation of Chemical Equilibria in Aqueous Solution) Viçosa: EdUFV, 2019 (in portuguese) in press.

PAIK, S-H, Understanding the Relationship Among Arrhenius, Brønsted-Lowry, and Lewis Theories, J. Chem. Educ., v.92, n. 9, p. 1484-1489. 2015.

PARTINGTON, J.R. History of chemistry. N. York: St Martin, 1961.

PO, H. N., The Henderson-Hasselbalch Equation: Its History and Limitations, J. Chem. Ed., v.78, n.11, p.1499-1503. 2001.

SZABADRARY, F. C. History of Analytical Chemistry. Oxford: Pergamon, 1996.

VENER, M.V.; LIBROVICH, N.B The structure and vibrational spectra of proton hydrates: as a simplest stable ion, J. Int. Rev. Phys. Chem., v. 28, n.3, p. 407-434. 2009.

VOGEL, A. I. SVEHLA, G. Vogel's Macro and semimicro qualitative inorganic analysis. $5^{\text {th }}$ ed. London: Longman Group, 1979. 